\title{
Prediction of Intensive Care Cases for COVID-19 Pandemic in Malaysia: An Artificial Neural Networks Approach
}

\author{
N.Z. Abidin ${ }^{1 *}$, A.A. Ahmarofi ${ }^{2}$ and N.Z. Zaibidi ${ }^{3}$ \\ ${ }^{1}$ Institute of Strategic Industrial Decision Modeling, School of Quantitative Sciences, College of Arts and Sciences, \\ Universiti Utara Malaysia, Sintok, Kedah, Malaysia \\ ${ }^{2}$ Faculty of Computer \& Mathematical Sciences, Universiti Teknologi MARA (UiTM) Kedah Branch, O8400 Merbok, \\ Kedah, Malaysia \\ ${ }^{3}$ School of Quantitative Sciences, College of Arts and Sciences, Universiti Utara Malaysia, Sintok, Kedah, Malaysia
}

\begin{abstract}
Coronavirus 2019 (COVID-19) pandemic in Malaysia is a part of the ongoing worldwide pandemic. The emergence of COVID-19 has led to high demand for intensive care services worldwide. However, the severity of COVID-19 patients that need intensive care unit (ICU) treatments requires details investigation. This study aims to predict the number of ICU cases due to COVID-19 disease in Malaysia. The prediction was done based on the data related to new, recovered, and treated cases which were collected from the website of the Ministry of Health Malaysia started from April until August 2020. Artificial Neural Networks Multilayers Perceptron Backpropagation (ANN-MLP-BPP) model was developed for predicting ICU cases based on the usage of the real set of data. The ANN-MLP-BPP model was validated by splitting the data into $80 \%$ for training and $20 \%$ for testing. The results show that with the increase in the number of undertreated cases, the number of predicted ICU will also be increased. The predicted ICU admission is almost equivalent to a 1 percent increment of the number of cases undertreated. These findings may help the frontline physicians in planning and handling the facilities management during the COVID-19 pandemic situation in the future.
\end{abstract}

Keywords: artificial neural networks; COVID-19; intensive care; prediction

\section{INTRODUCTION}

Coronavirus disease 2019 (COVID-19) is an infectious disease triggered by a newly discovered strain of coronavirus that causes severe respiratory illness (Wang et. al. 2020; Huang et al., 2020). Due to the seriousness of COVID-19, World Health Organisation (WHO) declared COVID-19 as a pandemic, and the first case of COVID-19 was reported in Wuhan, China in December 2019 (Zhu et. al., 2020; WHO, 2020). Based on the statistics, more than 30 million cases have been reported and nearly one million people worldwide have died of COVID-19 (John Hopkins University, 2020). The actual number of total death from COVID-19 is likely to be higher due to the testing shortages (Yelin et al., 2020).
The case of COVID-19 which was initially from Wuhan, China started in Malaysia when our neighbouring Singapore firstly reported its first positive case on 23rd January 2020. Starting from this date, eight close contacts were distinguished as being in Johor, Malaysia (Abdullah, 2020b). Related to the intensive care unit (ICU), the number of cases in the ICU is growing every day. Figure 1 presented a graph to illustrate the trends of the total number of active cases, the total number of discharge cases, and accumulated positive cases of COVID-19 in Malaysia for the period from 1 June until 20 August 2020. The first deadly patient in Malaysia after being treated under ICU treatment was reported on 17th March 2020, a case identified with the religious assembling 
in Seri Petaling. It is followed by another death from Sarawak on a similar date (Abdullah, 2020j; Abdullah, 2020k).

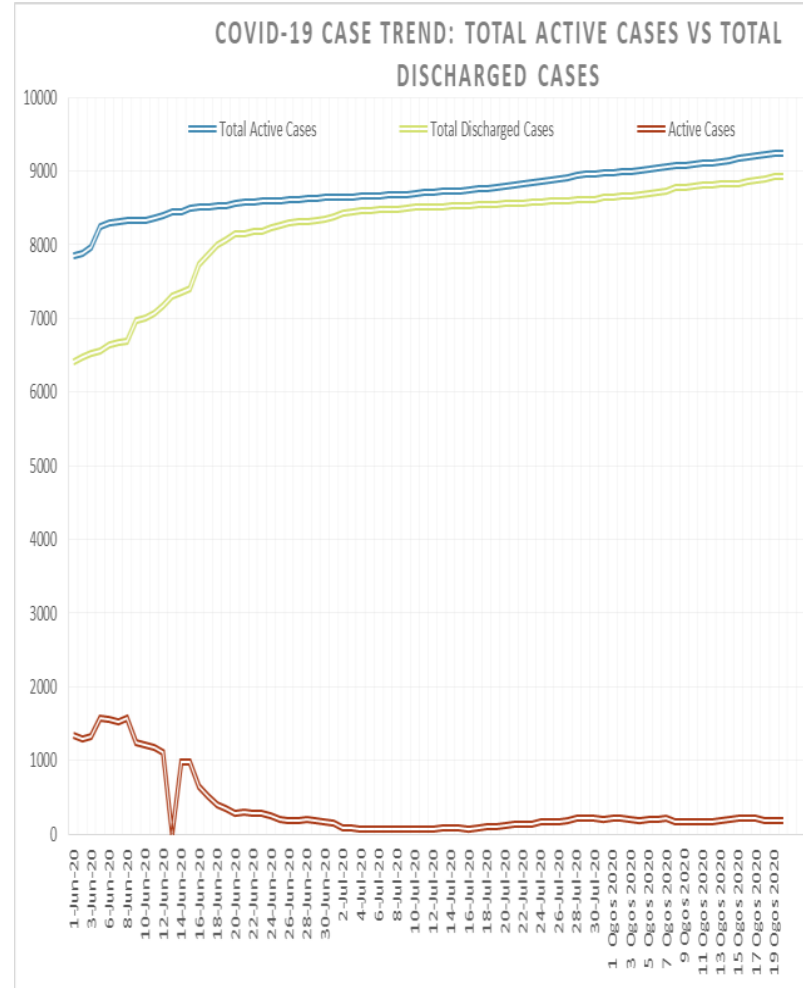

Figure 1. Trends of COVID-19 in Malaysia

This pandemic has developed interests from all areas of researches namely clinical, social, economics, and others. From the aspect of quantitative modeling, predictive models are useful for estimating the number of COVID-19 cases and deaths, as well as the resources needed, such as hospital patient beds and ICU beds, and supply-demand, such as personal protective equipment (PPE). Predictive modelling is a statistical method that attempts to predict future events or outcomes by examining patterns that are likely to predict future occurrences (Samarasinghe, 2016). Few predictive models have been developed to forecast the trend of COVID19 spreading (Jewell et. al., 2020; Sardar et. al., 2020; Yan et al., 2020). However, the predictive modelling that can forecast the number of ICU cases in Malaysia is still few. As a result, a study to forecast the number of ICU cases linked to COVID-19 is critical for public health planning and evaluating the effects of policy interventions. This study aims to predict the number of ICU cases due to COVID-19 disease in Malaysia.

The remainder of this paper is organised as follows: A review of works related to COVID-19 issues is presented in the next section. It is followed by a discussion on the methodology carried out in this paper. Results, discussion, and conclusion of the paper are presented at the end of the section.

\section{RELATED WORKS}

Prediction refers to the action of forecasting the future and uncertain cases (Mehrjerdi \& Aliheidary, 2014; Samarasinghe, 2016). A predictive technique is a process of making inferences from a dataset and normally extracted from a vast of historical data which is known as a data mining process (Kumar, 2013; Dzakiyullah, 2015). It is found that prediction is categorised as a machine learning technique to solve prediction problems. Theoretically, machine learning is an artificial intelligence method which mainly concerned with the development of algorithms that enable computers to perform learning processes based on historical data which is known as the data mining process Turban, Sharda, \& Delen, 2011). Methods such as decision tree, regression analysis, and artificial neural network (ANN) are among the wellestablished predictive methods in the literature. This section reviews the application of machine learning techniques that have been widely used in prediction studies related to COVID-19 issues. For example, Punn, Kumar \& Argawal (2020) developed machine learning and deep learning models to predict the future reachability of the COVID-2019 and its exponential behaviour across the nations. Besides, a study by Sujath, Chatterjee, and Hassanien (2020) predicted the spread of COVID-2019 in India based on the application of machine learning techniques. In this study, linear regression, multilayer perceptron, and vector auto-regression methods were used to anticipate the epidemiological example of the ailment and pace of COVID-2019 cases in India.

Decision tree (DT) is one of the popular decision support methods in machine learning techniques. It is a flow-chartlike tree graphical structure between the identified factors or rules and output to classify the related rules on the targeted output (Pradeepkumar \& Ravi, 2017). In terms of the application, DT has been used in many domains of COVID-19 studies. For instance, four different data mining techniques namely DT, Random Forests (RF), Logistic Model Trees (LMT), and Naive Bayes (NB) classifiers were used to develop a COVID-19 model based on the 482 records cases (Ali 2020). Furthermore, a study by Muhammad, Islam, Usman, and 
Ayon (2020) developed the data mining models based on the DT, support vector machine, naive Bayes, logistic regression, random forest, and K-nearest neighbour algorithms in predicting the COVID-19 infected patients' recovery in South Korea. Finally, Yoo et al. (2020) investigate the feasibility of using a deep learning-based decision-tree classifier that comprises three binary decision trees. Each tree is trained by a deep learning model with a convolution neural network based on the PyTorch frame for detecting COVID-19 from CXR images. The first decision tree classifies the CXR images as normal or abnormal. The second tree identifies the abnormal images that contain signs of tuberculosis, whereas the third does the same for COVID-19.

Artificial neural network (ANN) is a biologically inspired statistical method for data mining was developed by McCulloch and Pitts in 1943 through experiments and observations of the biological human brain (Turban et. al., 2011 Kumar, 2013; Samarasinghe, 2016). Theoretically, ANN can be defined as a mathematical estimation method inspired by the human biological neuron in the brain with learning parameters and network architecture for information processing (Venugopal \& Narendran, 1992; Azadeh et. al., 2014; Wang \& Jiang, 2017). The function of ANN is to predict the new occurrence based on a learning process of data (Kumar, 2013; Mehrjerdi \& Aliheidary, 2014). The application of ANN related to COVID-19 studies has been discussed by Mollalo, Rivera, and Vahedi (2020). This study examined the performance of multilayer perceptron (MLP) structure in ANN to predict the cumulative COVID-19 incidence rates across the continental United States. Furthermore, an artificial neural network-based curve fitting technique was proposed to predict the growing number of COVID-19 cases and deaths in four countries in the world; India, the USA, France, and United Kingdom (Tamang, Singh \& Datta, 2020). Finally, a forecasting model based on the statistical and artificial intelligence of autoregressive integrated moving average (ARIMA) and non-linear autoregressive artificial neural networks (NARANN) based approaches were proposed by Saba and Elsheikh (2020) to predict the prevalence of this COVID-19 pandemic in Egypt.

It is found that the ANN method is widely used compared to DT and regression analysis because ANN can model the data with high numbers of data and is more powerful to handle interactions among various variables (Turban et. al., 2011; Samarasinghe, 2016). Moreover, ANN performance improved faster than DT and regression analysis as the number of classes of categorical variables increased (Kim, 2008). These are the motivation for the selection of ANN to predict the ICU cases of COVID-19 in this study. Hence in this study, our interest is on the development of the predictive model to foresee the ICU admission for COVID-19 patients in Malaysia using the ANN approach.

\section{MATERIALS AND METHOD}

\section{A. Data Collection}

To construct the Artificial Neural Networks Multilayers Perceptron Backpropagation (ANN-MLP-BPP) model for predicting the ICU cases of COVID-19, a problem based on a real set of data was considered. The prediction of ICU cases was based on the three variables namely cured cases, undertreated cases, and new cases as presented in Table 1. The three variables were based on the secondary data obtained from the official website of the Ministry of Health $(\mathrm{MOH})$, Malaysia from $30^{\text {th }}$ April 2020 until 20 $0^{\text {th }}$ August 2020 (Ministry of Health Malaysia, 2020). The number of data involved in this research was 113 readings.

Table 1. Secondary data to develop ANN-MLP-BP model

\begin{tabular}{ll}
\hline List of data & \multicolumn{1}{c}{ Description } \\
\hline 1. Intensive care & $\begin{array}{l}\text { Intensive care units cater for patients } \\
\text { unit (ICU) } \\
\text { with severe life- } \\
\text { threatening illnesses and injuries, } \\
\text { which require constant care, close } \\
\text { supervision from life support } \\
\text { equipment and medication to } \\
\text { ensure normal bodily functions. } \\
\text { The patient is recovered and has been } \\
\text { discharged from the hospital. } \\
\text { The patient received treatment from } \\
\text { the nurse and doctor. }\end{array}$ \\
3. Undertreated \\
cases
\end{tabular}

\section{B. Research Process}

Figure 2 demonstrates the steps of developing the BP learning algorithm for the MLP network structure to predict the ICU cases. Subsequently, a feed-forward multilayer perceptron (MLP) network structure was established for the learning process to predict ICU cases. The learning process within the 
established MLP network structure was guided through the development of a learning algorithm. The MLP network structure was trained by the developed BP learning algorithm to circulate back at a different value between the output network and desired output.

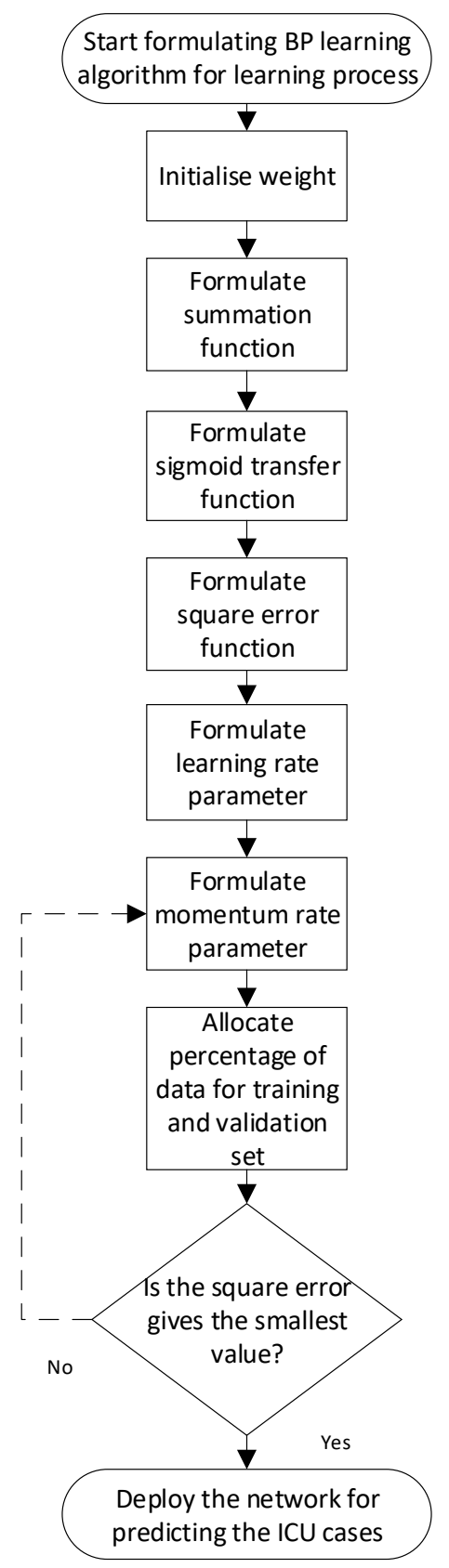

Figure 2. The flowchart of the backpropagation learning algorithm

The learning process of a BP learning algorithm was generated by the initialisation of connection weight. The connection weight value was initialised at this stage in representing the importance of each input parameter; cured, undertreated, and new cases towards the desired output of
ICU cases during the learning process. The value of the connection weight was initially set to a random value and no restriction of formulating the connection weight in a learning process. Thus, the value of the connection weight between the $i$ th input node and $j$ th hidden node in the MLP network structure to predict cycle time was formulated as the following Equation (1):

$$
w_{i j}=W_{I J}
$$

where,

$i=$ the number of input nodes at the input layer where $i=1,2, \ldots, I$

$j=$ the number of hidden nodes at the hidden layer where $j=1,2, \ldots, J$

On the other hand, the value of the connection weight between $j$ th hidden node and $k$ th output node was formulated as in Equation (2):

$$
w_{j k}=W_{J K}
$$

where,

$j=$ the number of hidden nodes at the hidden layer where $j=1,2, \ldots, J$

$k=$ the number of output nodes at the output layer where $k=1,2, \ldots, K$

The MLP network structure is developed based on the number of input node-the number of hidden node-the number of output nodes, $i-j-k$. In this research, the input layer has three nodes, the hidden layer has three nodes while the output layer has one node. Hence, the established network is a 3-2-1 MLP network structure. Figure 3 illustrates the flow of each step during the learning process within the feedforward MLP network structure to adjust the connection weight through the 3-2-1 MLP network structure. 


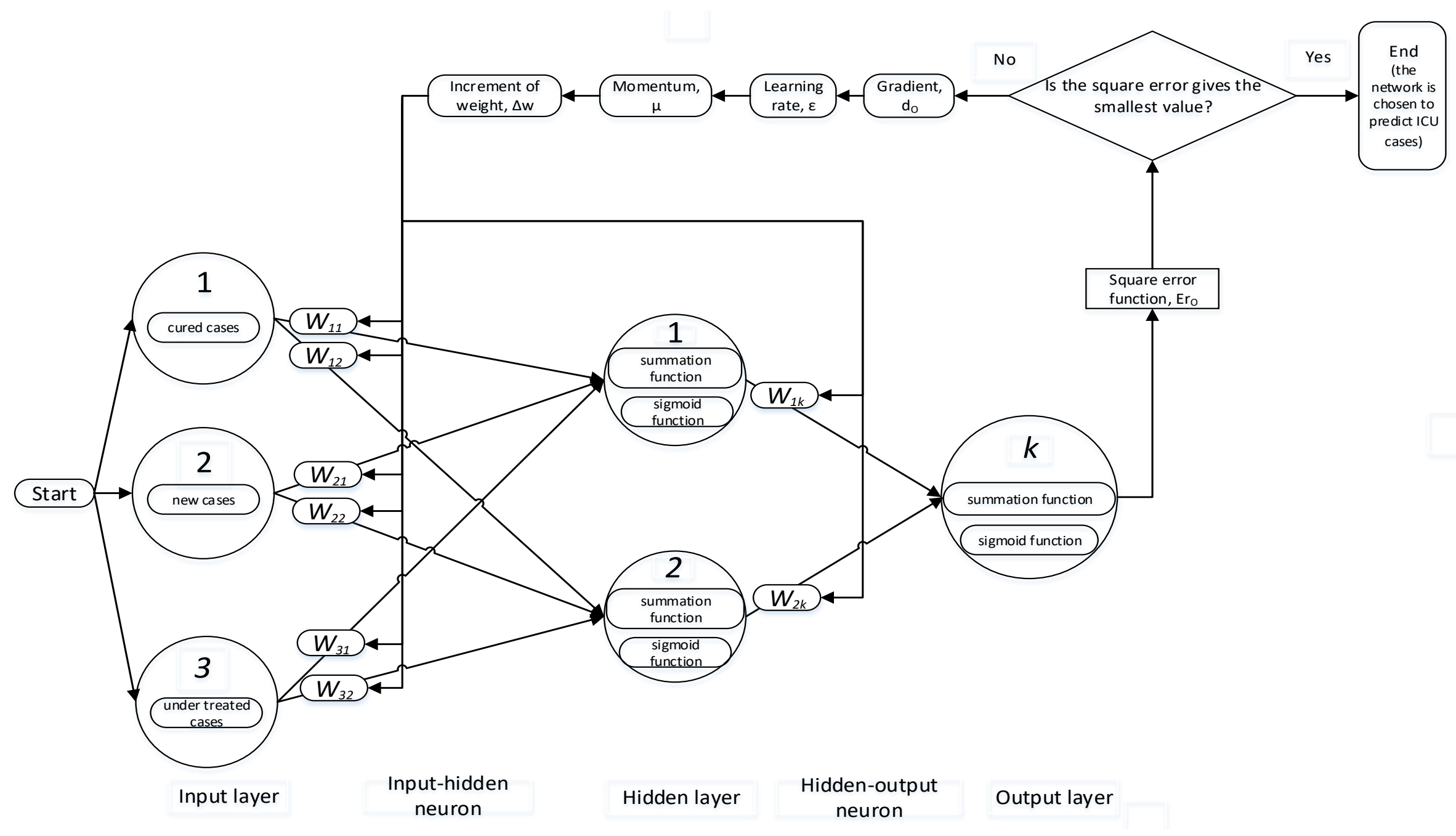

Figure 3. The flow of the learning process within the 3-2-1 multilayer perceptron network structure 
The flow for the learning process in the MLP network structure was generated in two directions which are feedforward and backpropagate. Both of the learning processes were iterated until the desired output of cycle time was achieved. After that, several learning parameters, i.e., summation function, sigmoid transfer function, square error function, learning rate parameter, and momentum rate parameter were formulated to adjust the connection weight. Finally, the smallest value of square error, $E$, is between the value of network output from the sigmoid function of $c$ th output node and desired output for predicting ICU cases. Thus, the connection weights were adjusted gradually to obtain the desired output in predicting ICU cases through summation and sigmoid functions. The adjustment of connection weight is then adjusted by the momentum rate once the speed of the learning process is controlled by the learning rate. The value of the momentum rate is normally within the range of $0 \leq|\mu|<1$ as highlighted by Turban et al. (2011). Subsequently, the increment of the connection weight for the next iteration is adjusted. Then, the feedforward learning process is repeated as shown in Figure 2. Therefore, the learning process is iterated until the network has a minimum value of square error, $E r$. A training process is established to adjust the connection weight from a set of data through a learning algorithm. Subsequently, the connection weight value from the training process for predicting cycle time is validated through a different set of data during the validation process. By assigning a higher percentage of data to the training set, the MLP network structure gives a better prediction performance result in the data learning process since the more the data are trained, the stronger the predictive relationship it has. Therefore, 80 percent of data is allocated for the training process while 20 percent is allocated for the validation process. The learning process of the MLP network structure is run iteratively according to the allocated data until the network has a minimum value of square error, $E r$. As a result, the predicted cycle time with the final connection weight $w_{i j}$ and $w_{j k}$ on the oth iteration of the learning process is determined as shown in Equation (3) as follows:

$$
\begin{gathered}
c_{n}=\left[w_{i j}\right]_{o} x_{B_{n}}+\left[w_{i j}\right]_{o} x_{C_{n}}+\left[w_{i j}\right]_{o} x_{D_{n}}+ \\
\sum_{j=1}^{J}\left[w_{j k}\right]_{o} \operatorname{sig}_{j}
\end{gathered}
$$

where,

$c_{n}=$ predicted ICU cases of $n$th day

$\left[w_{i j}\right]_{o}=$ final connection weight for $i$ th input node and $j$ th

hidden node of $o$ th iteration

$x_{B_{n}}=$ transformed value of $B_{n}$, i.e., cured cases for an $n$th day

$x_{C_{n}}=$ transformed value of $C_{n}$, i.e., undertreated cases for an $n$th day

$x_{D_{n}}=$ transformed value of $D_{n}$, i.e., new cases for an $n$th day $\left[w_{j k}\right]_{o}=$ final connection weight for the $j$ th hidden node and the $k$ th output node of $o$ th iteration

$\operatorname{sig}_{j}=$ the sigmoid value of the $j$ th hidden node

\section{RESULT AND DISCUSSION}

In the 3-2-1 MLP network structure, the value of the formulated momentum rate, $\mu$ is 0.333 based on the best-sofar momentum rate as highlighted by Ahmarofi, Ramli, Abidin, Jamil, and Shaharanee (2020). The connection weights for the ith input node to the jth hidden node, wij, and the jth hidden node to the kth output node, wjk, were initialised with random values 0.1, 0.3, 0.5, 0.7, 0.9, 1, and 1.5 as implemented by Ahmarofi, Ramli, and Abidin (2017) and Ahmarofi et al. (2020) since the determination of weight had no restriction in an ANN learning process. Besides, the value of the learning rate, $\varepsilon$, was set randomly to 0.2 while the value of momentum rate, $\mu=0.333$.

Furthermore, the data from $\mathrm{MOH}$ were randomly separated into 80 percent cases and 20 percent cases from different days between the train1 set and valid1 set for the 3-2-1 MLP network structure. The more data were allocated for training, the stronger the predictive relationship it has (Turban et al., 2011). Besides, most of the previous studies implement the ratio in their studies (Ahmarofi et al., 2017). Finally, the iteration of the learning process, $o$, for the 3-2-1 MLP network structure is accomplished once the result of the square error, $E r_{o}$, gives the smallest value. Subsequently, the final Ero for the experiment of the 3-2-1 MLP network structure is presented in Table 2.

Referring to Table 2, the smallest $E r_{o}$ for the 3-2-1 MLP network structure with 0.333 momentum rate and 0.2 learning rate is 0.001 during the $18^{\text {th }}$ iteration of the learning 
process which is obtained from $w_{i j}=1.5$ and $w_{j k}=1.5$. cured, undertreated, and new cases, the predicted ICU cases Consequently, the 3-2-1 MLP network is implemented for is expressed based on Equation (4) as follows: predicting ICU cases. If the hospital would like to predict the ICU cases for the next day, let say $n=120$ with the recorded $c_{120}=[-0.00023]_{18} x_{B_{120}}+[-0.00619]_{18} x_{C_{120}}$

$$
+[0.0094]_{18} x_{D_{120}}+0.98595
$$

Table 2. The $E r_{o}$ of the 3-2-1 MLP's experiment

\begin{tabular}{|c|c|c|c|c|c|c|c|c|}
\hline \multirow{2}{*}{$\begin{array}{c}\text { MLP } \\
\text { network } \\
\text { i-j-k }\end{array}$} & \multicolumn{2}{|c|}{$\begin{array}{l}\text { Connection } \\
\text { weight }\end{array}$} & \multirow{2}{*}{$\begin{array}{c}\text { Learning } \\
\text { rate } \\
\varepsilon\end{array}$} & \multirow{2}{*}{$\begin{array}{c}\text { Momentum } \\
\text { rate } \\
\mu\end{array}$} & \multicolumn{2}{|c|}{$\begin{array}{l}\text { Separation of data from } \\
\text { production lot number }\end{array}$} & \multirow{2}{*}{$\begin{array}{c}\text { Iteration } \\
\text { o }\end{array}$} & \multirow{2}{*}{$\begin{array}{c}\text { Final } \\
\text { square } \\
\text { error } \\
\text { Ero }\end{array}$} \\
\hline & $\mathbf{w}_{\mathbf{i j}}$ & $\mathbf{w}_{\mathbf{j k}}$ & & & $\operatorname{train}_{1}$ & valid $_{1}$ & & \\
\hline \multirow{7}{*}{$\begin{array}{c}3-2-1 \\
\text { network }\end{array}$} & 0.1 & 0.1 & \multirow{7}{*}{0.2} & \multirow{7}{*}{0.333} & \multirow{7}{*}{$80 \%$} & \multirow{7}{*}{$20 \%$} & 20 & 0.194 \\
\hline & 0.3 & 0.3 & & & & & 12 & 0.941 \\
\hline & 0.5 & 0.5 & & & & & 24 & 0.006 \\
\hline & 0.7 & 0.7 & & & & & 19 & 0.011 \\
\hline & 0.9 & 0.9 & & & & & 23 & 0.238 \\
\hline & 1 & 1 & & & & & 24 & 0.586 \\
\hline & 1.5 & 1.5 & & & & & 18 & 0.001 \\
\hline
\end{tabular}

As a result, the best-predicted ICU cases on the subsequent days based on the recorded cured, undertreated, and new cases are presented in Table 3 .

Table 3. The best-predicted ICU cases

\begin{tabular}{cccc}
\hline $\begin{array}{c}\text { Predicted } \\
\text { ICU }\end{array}$ & $\begin{array}{c}\text { Cured } \\
\text { Cases }\end{array}$ & $\begin{array}{c}\text { New } \\
\text { Cases }\end{array}$ & $\begin{array}{c}\text { Under Treated } \\
\text { Cases }\end{array}$ \\
\hline 3 & 17 & 14 & 210 \\
3 & 3 & 7 & 213 \\
3 & 27 & 12 & 207 \\
3 & 5 & 8 & 223 \\
2 & 7 & 15 & 103 \\
12 & 60 & 31 & 1189 \\
12 & 31 & 37 & 1218 \\
12 & 44 & 47 & 1213 \\
12 & 59 & 22 & 1210 \\
13 & 73 & 17 & 1247 \\
14 & 110 & 16 & 1410 \\
15 & 96 & 67 & 1523 \\
16 & 74 & 39 & 1584 \\
\hline
\end{tabular}

For example, if the number of cured cases is 17 cases, while 14 and 210 for the new cases and undertreated cases, respectively, it is predicted that ICU cases would be 3 cases as presented in Table 3. Another finding is, if the cured cases are 60 cases, while 31 and 1189 for the new cases and undertreated cases, respectively, it is predicted that ICU cases would be 12 cases. Moreover, it is found that when the number of under-treated cases increases, the predicted ICU cases will contribute to 1 percent from the cases. The trend of the number of under-treated and the respective predicted ICU are presented in Figure 4. For instance, when the number of undertreated is 1189 and 1410 cases, the predicted ICU cases are 12 and 14 cases, respectively.

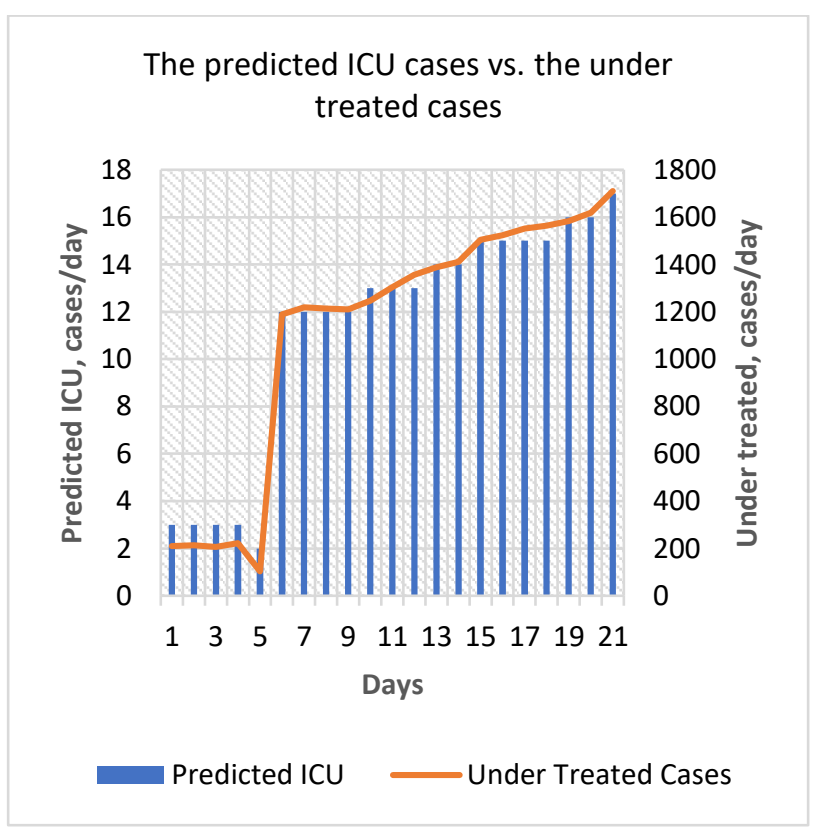

Figure 4. The number of predicted ICU cases compared to the number of undertreated cases

The findings in this research are yet to be verified as the trend of COVID-19 is still developing. However, one of the related studies with ours was done by (Lewnard et al., 2020). 
In this study, it is highlighted that hospitalised COVID-19 patients in the US will stay longer in the hospital and facing higher rates of ICU admission than patients in China. The finding also shows that the probabilities of ICU admission, hospital stay, and mortality were high among the residents of California and Washington who were admitted to the hospital with COVID-19. Finding from the Lenward's study supported our findings that also shows with the increment in the number of undertreated cases with COVID-19, the number of ICU admission of patients is also increasing.

Importantly, this study may give some significant findings that can be used as guidance for health providers in preparing the facilities needed in the future to overcome the pandemic issues. It includes the preparation in terms of the number of health staff to be appointed, the number of hospital beds to be provided and the number of centres to be built. This is very important to have good planning and arrangement to avoid the severe condition that needs ICU treatment.

\section{CONCLUSION AND FUTURE WORKS}

The artificial neural network is considered one of the efficient methods in processing huge data sets that can be analysed computationally to reveal patterns, trends, predictions, and forecasting. This study predicted ICU admission associated with COVID-19 infection in Malaysia using the ANN-MLPBPP model. Based on the findings, it shows that when the number of under-treated cases increases, the predicted ICU cases will represent a 1 percent increment from the cases. All the conclusions are made as per the forecasts obtained as a result of the applied ANN method. Though the data of cases used in the study is based on reliable sources, our model can be readily enhanced or retrained using additional data from the other country as future research.

\section{ACKNOWLEDGEMENT}

This research received no specific grant from any funding agency in the public, commercial, or non-profit sectors.

\section{REFERENCES}

Abdullah, NH 2020b, Tindakan KKM bagi pengesanan kontak (contact tracing) kepada kes pertama positif novel Coronavirus di negara Singapura [Press release] (2020), viewed 30 March 2020, <http://www.moh.gov.my/index.php/database_stores/st ore_view_page $/ 21 / 1300>$.

Abdullah, NH 2020j, Situasi semasa jangkitan penyakit Coronavirus 2019 (COVID-19) di Malaysia [Press release] (2020), viewed 30 March 2020, <https://kpkesihatan.com/2020/03/o9/kenyataanakhbar-kpk-9-mac-2020-situasi-semasa-jangkitanpenyakit-coronavirus-2019-covid-19-di-malaysia/> .

Abdullah, NH 2020k, Situasi semasa jangkitan penyakit Coronavirus 2019 (COVID-19) di Malaysia [Press release](2020), viewed 30 March 2020, <https://kpkesihatan.com/2020/03/17/kenyataanakhbar-ybmk-17-mac-2020-situasi-semasa-jangkitanpenyakit-coronavirus-2019-covid-19-di-malaysia/>.

Ahmarofi, AA, Ramli, R \& Abidin, NZ 2017 'Predicting completion time for production line in a supply chain system through artificial neural networks', International
Journal of Supply Chain Management, no. 6, vol. 3, pp. 8290.

Ahmarofi, AA, Ramli, R, Abidin, NZ, Jamil, JM \& Shaharanee, IN 2020, 'Variation on the numbers of hidden nodes through mutilayer perceptron networks to predict the cycle time', Journal of Information, Communiacation and Technology, no. 19, vol.1, pp. 1-19.

Ali, K 2020, Coronavirus Infectious Disease (COVID-19) Modeling: Evidence of Geo-graphical Signals, viewed 4 April 2020, <https://ssrn.com/abstract $=3568425$ or http://dx.doi.org/10.2139/ssrn.3568425>.

Azadeh, A, Shoushtan, KD, Saberi, M \& Teimoury, E 2013, An integrated artificial neural networks and system dynamics approach in support of the viable system model to enhance industrial intelligence: the case of a large broiler industry, viewed 5 May 2020, <http:// onlinelibrary.wiley.com. doi: 10.1002/sres.2199/abstract $>$.

Dzakiyullah, RNR 2015, 'Production quantity estimation using improved artificial neural networks', Unpublished dissertation, Universiti Teknikal Malaysia, Melaka, Malaysia. 
Huang C, Wang Y, Li X, Ren L, Zhao J, Hu Y, Zhang, L, Fan, $\mathrm{G}, \mathrm{Xu}, \mathrm{J}, \mathrm{Gu}, \mathrm{X}$ \& Cheng, $\mathrm{Z}$ 2020, 'Clinical features of patients infected with 2019 novel coronavirus in Wuhan, China', Lancet, vol. 395, no. 10223, pp. 497-506.

Jewell, NP, Lewnard, JA \& Jewell, BL 2020, 'Predictive mathematical models of the COVID-19 pandemic: Underlying principles and value of projections', Jama, vol. 323, no. 19, pp. 1893-1894.

Johns Hopkins University Coronavirus Resource Center, 2020, viewed 7 August 2020, <https://coronavirus.jhu.edu.>.

Kim, YS 2008, 'Comparison of the decision tree, artificial neural network, and linear regression methods based on the number and types of independent variables and sample size', Expert Systems with Applications, no. 34, pp. 12271234 .

Kumar, S 2013, Neural Networks: A Classroom Approach, New Delhi, McGraw Hill.

Lewnard, JA, Liu, VX, Jackson, M., Schmidt, MA, Jewell, BL, Flores, JP, Jentz, C, Northrup, GR, Mahmud, A, Reingold, AL, Petersen, M, Jewell, N, Young, S \& Bellows, J 2020, 'Incidence, clinical outcomes, and transmission dynamics of severe coronavirus disease 2019 in California and Washington: Prospective cohort study', BMJ, no. 369, pp. 1-10.

Mehrjerdi, YZ \& Aliheidary, T 2014, 'System dynamics and artificial neural networks integration: A tool to evaluate the level of job satisfaction in services', International Journal of Industrial Engineering and Production Research, no. 25, vol. 1, pp. 13-26.

Ministry of Health Malaysia 2020, viewed 5 July 2020, <https://www.moh.gov.my/>.

Mollalo, A, Rivera, KM \& Vahedi, B 2020, 'Artificial neural network modeling of novel coronavirus (COVID-19) incidence rates across the continental United States', International Journal of Environmental Research and Public Health, vol. 17, no. 12.

Muhammad, LJ, Islam, MM., Usman, SS \& Ayon, SI, 2020 'Predictive data mining models for novel coronavirus (COVID 19) infected patients' recovery', SN Computer Science, vol. 1, no. 206, pp. 1-7.

Punn, NS, Sonbhadr, SK \& Agarwal, S 2020, COVID-19 Epidemic Analysis using Machine Learning and Deep Learning Algorithms, viewed 25 August 2020, <https://doi.org/10.1101/2020.04.08.20057679>.

Pradeepkumar, D \& Ravi, V 2017, 'Forecasting financial time series volatility using particle swarm optimization trained quantile regression neural network', Applied Soft Computing, vol. 58, pp. 35-52.

Saba, AL \& Elsheikh, AH 2020, 'Forecasting the prevalence of COVID-19 outbreak in Egypt using nonlinear autoregressive artificial neural network', Process Safety and Environmental Protection, vol. 141, pp. 1-8.

Samarasinghe, S 2016, Neural networks for applied sciences and engineering: from fundamentals to complex pattern recognition, Auerbach Publication, New York.

Sardar, T, Nadim, SS, Rana, S \& Chattopadhyay, J 2020, 'Assessment of lockdown effect in some states and overall India: A predictive mathematical study on COVID-19 outbreak', Chaos, Solitons \& Fractals, vol. 139, no. 110078.

Sujath, R, Chatterjee, JM \& Hassanien, AE 2020, 'A machine learning forecasting model for COVID-19 pandemic in India', Stochastic Environmental Research and Risk Assessment, vol. 34, pp. 959-972.

Tamang, SK, Singh, P, Singh \& Datta, B 2020 'Forecasting of Covid-19 cases based on prediction using artificial neural network curve fitting technique', Global J. Environ. Sci. Manage, vol. 6(SI), pp. 53-64.

Turban, E, Sharda, R \& Delen, D 2011, Decision Support and Business Intellligence System, Pearson Education Inc., New Jersey.

Venugopal, V \& Narendran, TT 1992, 'Neural network model for design retrieval in manufacturing systems' Computers industry, vol. 20, pp. 11-20.

Wang, C \& Jiang, P 2017, 'Deep neural networks based order completion time prediction by using real-time job shop RFID data', Journal of Intelligent Manufacturing, pp. 1-16.

Wang D, Hu B, Hu C, Zhu F, Liu X, Zhang J, Wang, B, Xiang, H, Cheng, Z, Xiong, Y \& Zhao, Y 2020 'Clinical characteristics of 138 hospitalized patients with 2019 novel coronavirus-infected pneumonia in Wuhan, China', JAMA, vol. 323, no. 11, pp. 1061-1069.

WHO 2020, Coronavirus disease 2019 (COVID-19) Situation Report 2020, viewed 20 August 2020, <https://www.who.int/emergencies/diseases/novelcoronavirus-2019/situation-reports/>.

Yan, L, Zhang, HT, Goncalves, J, Xiao, Y, Wang, M, Guo, Y., \& Huang, X 2020, 'An interpretable mortality prediction model for COVID-19 patients', Nature Machine Intelligence, pp. 1-6.

Yelin I, Aharony N, Shaer-Tamar E, Argoetti A, Messer E, Berenbaum D, Shafran, E, Kuzli, A, Gandali, N, Shkedi, O \& Hashimshony, T 2020, Evaluation of COVID-19 RT-qPCR test in multi-sample pools, Clinical Infectious Diseases, 
viewed 1 October 2020,

< https://doi.org/10.1093/cid/ciaa531>.

Yoo, SH, Geng H, Chiu TL, Yu, SK, Cho DC, Heo J, Choi MS,

Choi, IH, Cung, Van C, Nhung NV, Min BJ \& Lee H 2020,

'Deep learning-based decision-tree classifier for COVID-19

diagnosis From chest X-ray imaging', Front. Med., vol. 7, no.

427, pp. $1-8$.

Zhu N, Zhang D, Wang W, Li X, Yang B, Song J, Zhao, X, Huang, B, Shi, W, Lu, R \& Niu, P 2019, 'A novel coronavirus from patients with pneumonia in China', N Engl J Med., vol. 382, no. 8, pp. 727-33. 